\title{
Linkage between the Arctic Oscillation and winter extreme precipitation over central-southern China
}

\author{
Rui Mao ${ }^{1,2, *}$, Dao-Yi Gong ${ }^{1}$, Jing Yang ${ }^{1}$, Jing-Dong Bao ${ }^{2}$ \\ ${ }^{1}$ State Key Laboratory of Earth Surface Processes and Resource Ecology, and ${ }^{2}$ Department of Physics, \\ Beijing Normal University, Beijing 100875, PR China
}

\begin{abstract}
In this study, we analyzed the relationship between the Arctic Oscillation (AO) and extreme precipitation events over China during boreal winters from 1954 to 2009. The extreme precipitation events are defined as those with daily precipitation above the 80th (or 90th) percentiles. The AO shows a significantly positive correlation with the frequency of extreme precipitation events over China during January to February. Of all 287 stations in China, 238 stations have positive correlation coefficients and 82 stations are positively significant above the $95 \%$ confidence level. These stations that have significantly positive correlation are mainly located over central-southern China. The correlation between the AO and the average frequency of extreme precipitation events over central-southern China is 0.49 , which is significant at the $99 \%$ confidence level. This correlation is still significant even when the El Niño/Southern Oscillation signal is excluded from the time series. In association with the AO-precipitation extreme linkage, the Middle East jet stream (MEJS) and the southern branch trough (SBT) over the Bay of Bengal covary consistently. A positive AO phase is accompanied by a stronger than normal MEJS and a deepened SBT. The deepened SBT enhances synoptic scale disturbances in vertical motions in the low to middle troposphere over central-southern China. More moisture transport by the deepened SBT and active synoptic scale disturbances in vertical motion over central-southern China would provoke more extreme precipitation events there.
\end{abstract}

KEY WORDS: Arctic Oscillation $\cdot$ Extreme precipitation event $\cdot$ South branch trough $\cdot$ Middle East jet stream $\cdot$ Central-southern China

\section{INTRODUCTION}

Arctic Oscillation (AO, also known as the northern annular mode) is the primary mode of internal atmospheric dynamics over the extratropical northern hemisphere, with a quasi-barotropic structure from the surface to the lower stratosphere. It becomes most active during cold seasons (November-April) (Thompson \& Wallace 1998). Fluctuations in the AO create a seesaw pattern in which atmospheric pressure and mass around north polar regions and midlatitudes change in an out-of-phase way. For instance, a positive $\mathrm{AO}$ phase is accompanied by low pressure over the north polar regions and high pressure at the mid-latitudes, and these feature are reversed in a negative AO phase.

Many studies have shown that the AO has marked impacts on global climate. During the winter season, the AO signal is reflected in fields like surface temperature in the northern hemisphere (Thompson \& Wallace 2001), precipitation in China (Gong \& Wang 2003), sea ice over north polar and sub-polar regions (Wang \& Ikeda 2000), and lower tropospheric circulations including the East Asian winter monsoon, Aleutian low, and Siberian high (Gong et al. 2001, Wu \& Wang 2002). During the spring season, the AO is 
closely related to dust storm frequency in northeast Asia (Gong et al. 2006, Mao et al. 2011a, Mao et al. $2011 \mathrm{~b}$ ), and even has a lag effect on the following summer monsoon rainfall in East Asia (Gong \& Ho 2003, Gong et al. 2011). The majority of previous studies have emphasized the AO's effect on seasonal mean climate. A few studies have analyzed possible linkages between AO and extreme weather/climate events, including cold air activity and blocking activity throughout the hemisphere (Thompson \& Wallace 2001), synoptic temperature variance over East Asia (Gong et al. 2004), extreme temperatures in the northeastern United States and Canada (Wettstein \& Mearns 2002), and synoptic scale disturbances in East Asia (Gong et al. 2006).

Previous studies revealed that AO is linked to monthly and seasonal precipitation amount over central-southwestern China during winter, with a statistically positive correlation (Gong \& Wang 2003). However, few studies have addressed the linkage between $\mathrm{AO}$ and precipitation extremes over China. In some case studies, it has been suggested that the AO was related, at least in part, to the extraordinarily frequent and long-lasting snowstorms over central-southern China in January 2008 (Wen et al. 2009). Also, the AO is accompanied by significant changes in the southern branch of the westerlies over the southern flank of the Tibetan Plateau during winter, which has an important influence on large-scale winter precipitation events over China via its control over water vapor supply and weather activity (Suo \& Ding 2009, Zhang et al. 2009). Therefore, we hypothesize that the winter $\mathrm{AO}$ has had a robust influence on extreme precipitation events over China during recent decades. The main goal of present study is to investigate the statistical linkage between the $\mathrm{AO}$ and extreme precipitation events over China during the period 1954-2009, and to investigate the related large-scale circulation and climate features observed.

This study is organized as follows. Section 2 describes the data and method used. In Section 3, the statistical relationship between the AO and precipitation extremes over China is analyzed, and is compared with the relationship between precipitation extremes and the El Niño/Southern Oscillation (ENSO). Section 4 analyzes atmospheric circulation anomalies observed in conjunction with the AOprecipitation links, and Section 5 analyzes corresponding synoptic scale disturbances. Finally, a discussion and a summary are provided in Sections 6 and 7 , respectively.

\section{DATA AND ANALYSIS}

\subsection{Data}

The station daily precipitation dataset used in this study was obtained from the China Meteorological Administration. This dataset covers a time period from 1954 to 2009 . We firstly screened the data because there are some missing values in this dataset. These missing values do not allow construction of time series such as for extreme precipitation frequency, which typically require complete datasets. Thus, stations that have missing values are all omitted. Among more than 700 stations, we selected 287 stations for which the dataset is complete.

The monthly AO index proposed by Li \& Wang (2003) is used in this study, which is the difference in surface pressure between $35^{\circ} \mathrm{N}$ and $65^{\circ} \mathrm{N}$ around the hemisphere based on the National Centers for Environmental Prediction and National Center for Atmospheric Research (NCEP/NCAR) monthly reanalysis dataset. This AO index has a more symmetric correlation with surface pressure anomalies around the hemisphere than does the leading empirical orthogonal function of Thompson \& Wallace (1998) (Angell, 2006). The AO index is available at www.lasg.ac.cn/ staff/ljp/data-NAM-SAM-NAO/NAM-AO.htm. The influence of ENSO signal on precipitation extremes is also considered in this study. The ENSO signal is represented using monthly Niño 3.4 sea surface temperature (SST). That is the mean of the SST anomalies over the area of $5^{\circ} \mathrm{N}$ to $5^{\circ} \mathrm{S}$ and $170^{\circ}$ to $120^{\circ} \mathrm{W}$. Time series of the AO index and ENSO index are constructed from averaged monthly values.

In order to analyze atmospheric circulation variations associated with AO changes, the NCEP/NCAR reanalysis dataset is used in the present study. The physical variables analyzed include specific humidity, horizontal wind, and geopotential at 8 standard pressure levels, namely, 1000, 925, 850, 700, 600, 500, 400, and $300 \mathrm{hPa}$. All variables have a spatial resolution of $2.5^{\circ}$ latitude $\times 2.5^{\circ}$ longitude. In addition, the water vapor flux within the atmospheric column used for measuring the water vapor transport is computed by vertically integrating data from surface to $300 \mathrm{hPa}$, following the method of Zhou \& Yu (2005). All the datasets described above cover the period 1954-2009.

\subsection{Analysis}

To delineate the linkage between $\mathrm{AO}$ and extreme precipitation events, we defined extreme precipita- 
tion frequency by percentiles as follows. For a given station for a given season, (1) the 80th percentile of daily precipitation during the reference period 19712000 is measured and then used as the threshold value; $_{i}(2)$ when a daily precipitation exceeds the threshold value, this day is classified as an extreme precipitation event; (3) the number of days with daily precipitation exceeding the threshold is counted year by year, and finally (4) the time series of the frequency of extreme precipitation events is constructed (hereafter referred to as P80th). To highlight lower probability events, we also analyzed extreme precipitation events using a stricter threshold of the 90th percentile (hereafter referred to as P90th).

Regarding the choice of the threshold of extreme events, it is worth noting that a stricter threshold of the 90th percentile or the 95th percentile is usually employed. In this study, however, we mainly used the 80th percentile for analyzing AO-extreme precipitation links. This choice is determined by the fact that use of the 80th percentile to define the extreme precipitation events identifies more stations with a significantly positive correlation between $\mathrm{AO}$ and extreme precipitation frequency than when using the 90th percentile and the 95th percentile. Of all 287 stations in China, there are 59, 46 and 32 stations with significantly positive correlations, using the 80th percentile, the 90th percentile, and the 95th percentile, respectively, to define the extreme precipitation frequency (figure not shown). Moreover, there are in several years with no extreme precipitation event when using the 90th percentile and the 95th percentile. This phenomenon arises from the facts that (1) precipitation is highly variable, and (2) occurrence of heavy rain in winter is notably less frequent than in summer. Thus, a stricter threshold such as 90th or 95th percentile would yield very small values for extreme precipitation frequency for some winters, which would result in spurious correlations. In contrast, the 80th percentile produces a moderately larger number of extreme precipitation events in each year, yielding a more stable AO-climate relationship which can be analyzed with greater confidence. Therefore, the 80th percentile (or the 20th percentile) is also used as the threshold in this study when computing the extreme event frequency of other atmospheric variables.

Many previous studies have showed that winter climates over East Asia could be impacted by the ENSO. For instance, Zhang \& Sumi (2002) showed that there are positive precipitation anomalies in winter over southern areas of China during the mature phase of El Niño. The ENSO often develops into a mature phase in boreal winter. Its influence on winter precipitation might conceal or distort the AOrelated signals. In the present study we compared the precipitation anomalies solely associated with $\mathrm{AO}$ and ENSO. In order to obtain the precipitation anomalies solely associated with the $\mathrm{AO}$, we regress the 2 time series of $\mathrm{AO}$ index and precipitation onto the ENSO index. The 2 residuals of original time series minus the regression estimation are regarded as the ENSO-free components, linearly speaking. Then the results of correlation and regression analysis of these 2 residuals are considered as the precipitation anomalies solely associated with the AO. Since climate changes (such as the monthly and seasonal mean circulations) in mid-high latitudes are quasilinearly related to the ENSO, this treatment of the ENSO signal should work well (Hoerling et al. 1995). Similarly, in order to obtain the precipitation anomalies solely associated with the ENSO, the 2 time series of precipitation and ENSO index are regressed onto the AO index. The 2 residuals are regarded as the AO-free components, linearly speaking. Then the results of correlation and regression analysis of these 2 residuals are considered as the precipitation anomalies solely associated with the ENSO. It should be pointed out that here we did not consider the possible influence of AO-ENSO interactions (Quadrelli \& Wallace 2002, Nakamura et al. 2006).

\section{RELATIONSHIP BETWEEN AO AND EXTREME PRECIPITATION EVENTS}

\subsection{Correlation between AO and P80th}

In order to identify whether there are statistical AO-extreme precipitation links, we first investigated the correlation between $\mathrm{AO}$ and P80th averaged over China. The AO is most active during winter season and is confined to the period October-March. To take into account the possible time-lag relationship between $\mathrm{AO}$ and precipitation, we computed their cross-correlation with 5 mo delay. Results are shown in Fig. 1. Among all months analyzed, a significantly simultaneous AO-P80th relationship can be found only in January and February. In other months, the AO-P80th relationship is weak, and not significant. The simultaneous correlation between $\mathrm{AO}$ and P80th is 0.32 in January and 0.22 in February; these results are significant above the $90 \%$ confidence level. When averaged for January and February, the AO-P80th correlation becomes 0.38 , significant above the $99 \%$ confidence level 

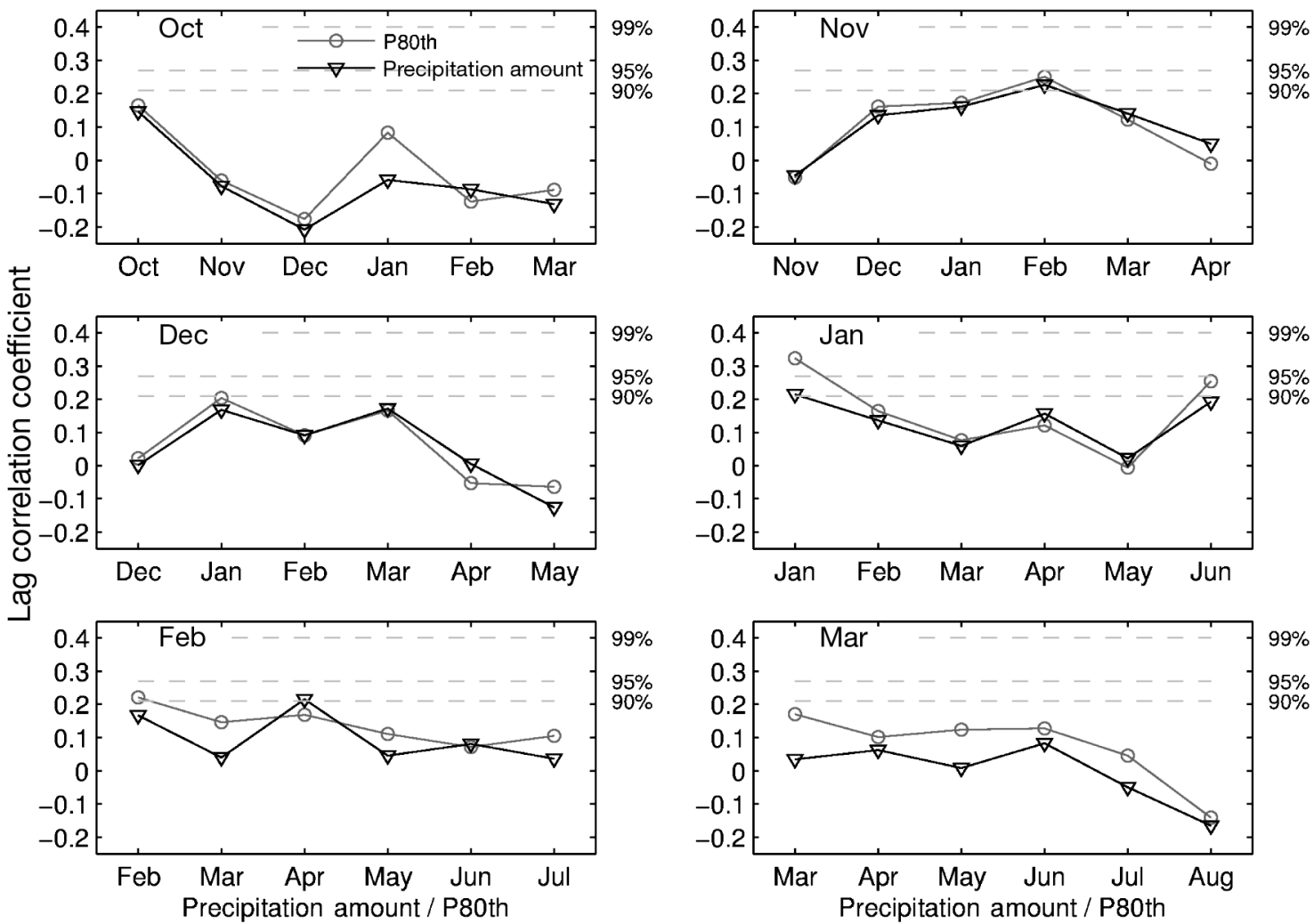

Fig. 1. Time lag correlations (R-values) between Arctic Oscillation (AO) in different months and the frequency of extreme precipitation (P80th) and precipitation amount. Dashed lines: confidence levels

(Table 1). We also examined the AO-P90th relationship, and found that this is also significant only in January and February (figure not shown). The simultaneous correlation between $\mathrm{AO}$ and P90th is 0.31 during January and 0.25 during February; again these results are significant above the $90 \%$ confidence level. When averaged for January to

Table 1. Correlations (R-values) between Arctic Oscillation (AO) and frequencies of extreme precipitation (daily precipitation $>$ 80th or 90th percentile: P80th and P90th, respectively), precipitation amount, and strong southern branch trough (SBT) frequency during January to February, after and before excluding ENSO-related components. Precipitation data is averaged over central-southern China (parentheses: all China). All values are significant at the $99 \%$ confidence level

\begin{tabular}{|lccc|}
\hline P80th P90th & $\begin{array}{c}\text { Precipitation } \\
\text { amount }\end{array}$ & $\begin{array}{c}\text { Strong SBT } \\
\text { frequency }\end{array}$ \\
\hline \multicolumn{3}{|l}{ ENSO-excluded series } \\
$\begin{array}{l}0.54(0.43) \quad 0.54(0.44) \\
\text { Original series }\end{array}$ & $0.50(0.38)$ & 0.55 \\
$0.49(0.38) \quad 0.47(0.38)$ & $0.45(0.31)$ & 0.55 \\
\hline
\end{tabular}

February, the AO-P90th correlation is 0.38, significant at the $99 \%$ confidence level. These similar features in P90th and P80th suggest a statistical relationship between $\mathrm{AO}$ and precipitation extremes in January to February. Thus, in the following analysis, we only investigate the AO-precipitation links in January to February, and the winter mean is defined as the average of January and February.

In addition to the precipitation extremes, we analyzed the linkage between $\mathrm{AO}$ and precipitation. In Fig. 1, the correlations for AO-P80th are plotted together with those for AO-precipitation. The simultaneous correlation between $\mathrm{AO}$ and precipitation amount is 0.21 during January and 0.17 during February. Although these values are not significant, the mean total winter precipitation yields a correlation of 0.31 , which is significant above the 95\% confidence level (Table 1). Overall, the AOprecipitation linkage is consistent with AO-P80th relationship.

Secondly, we computed the correlation for each station to show spatial features of the AO-P80th relationship (Fig. 2a). As seen in the figure, positive correlations cover a large part of China and nega- 

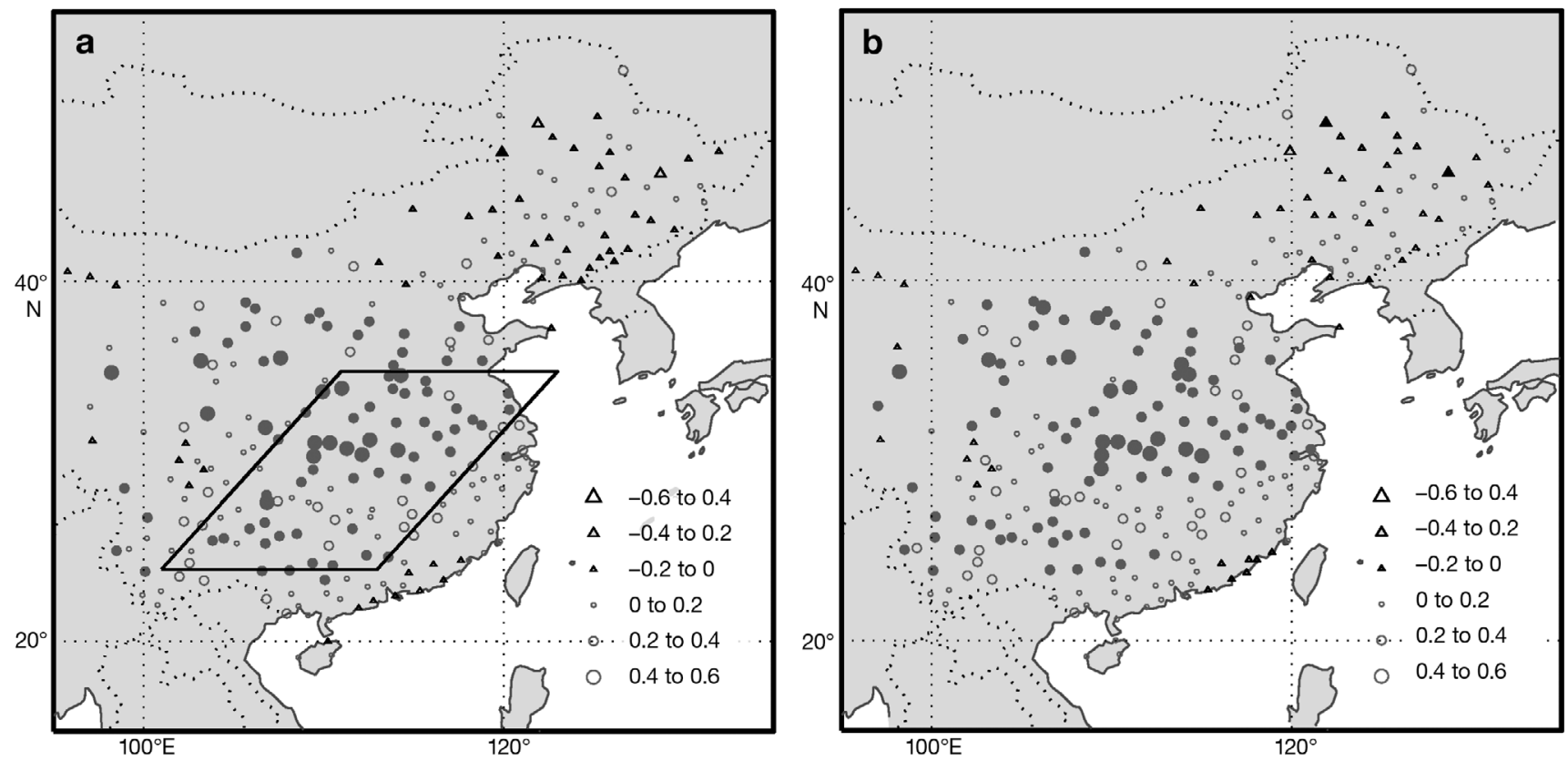

Fig. 2. Correlation (R-values) between Arctic Oscillation (AO) and (a) frequency of extreme precipitation (P80th), (b) precipitation amount in January to February. Triangles: negative values; circles: positive values. Filled circles (triangles): positive (negative) correlations above the $95 \%$ confidence level. In (a), the domain enclosed by solid lines is central-southern China, as defined in this study

tive correlations occur only in the northeast. Of all 287 stations, 238 stations have positive correlations and 49 stations have negative correlations. Among all stations, $82(104)$ stations are positively significant at the $95 \%(90 \%)$ confidence level. The stations with significantly positive correlation are mainly located in central-southern China (enclosed by solid lines in Fig. 2a, approximately within the boundaries $24^{\circ}-35^{\circ} \mathrm{N}$ and $101^{\circ}-123^{\circ} \mathrm{E}$ ). To get more details on temporal changes in the occurrence of precipitation extremes, we constructed a time series of January-February P80th over central-southern China and compared these with the JanuaryFebruary AO index. As shown in Fig. 3a, the 2 time series display an in-phase relationship. When AO is in a positive phase (such as the early 1990s) there the value of P80th tends to be higher. Similarly, when $\mathrm{AO}$ is in a negative phase, during years such as 1958, 1960, 1963, 1966, 1969, and 1977, values of P80th are also lower. Their in-phase co-variations are confirmed by correlation analysis. The correlation between them is 0.49 , significant at the $99 \%$ confidence level (Table 1). Because there are strong linear trends in both time series, which could produce a high correlation between $\mathrm{AO}$ index and P80th over the central-southern China even if there was no physical linkage between them, we removed the linear trends of both time series and then calcu- lated the correlation between them. The newly derived correlation coefficient is 0.45 , which is still significant at the $99 \%$ confidence level. Therefore, the AO is significantly associated with the changes in P80th over central-southern China.

Finally, we investigated spatial features of the AO-precipitation relationship (Fig. 2b). Similar to the AO-P80th correlation, positive correlations between $\mathrm{AO}$ and precipitation are spread over most of China, and only a few stations in the northeast have negative correlations. The significantly positive correlations are also centered over central-southern China. Of all 287 stations, 230 stations have positive correlations, and 92 (113) stations are positively significant at the $95 \%(90 \%)$ confidence level. We also computed a time series of mean precipitation averaged over central-southern China and compared this with the time series of the AO index. As shown in Fig. 3a, the AO index and precipitation display a strong in-phase relationship. The AO undergoes decadal changes, with a low-value period during 1954-1986, a markedly high-value period during 1987-1995, and a relatively high-value period during 1996-2009. Precipitation varies accordingly, with low values in 1954-1986, markedly high values in 1987-1995 and relatively high values in 19972009. The data yield a correlation of 0.45 , significant at the $99 \%$ confidence level (Table 1). After filtering 

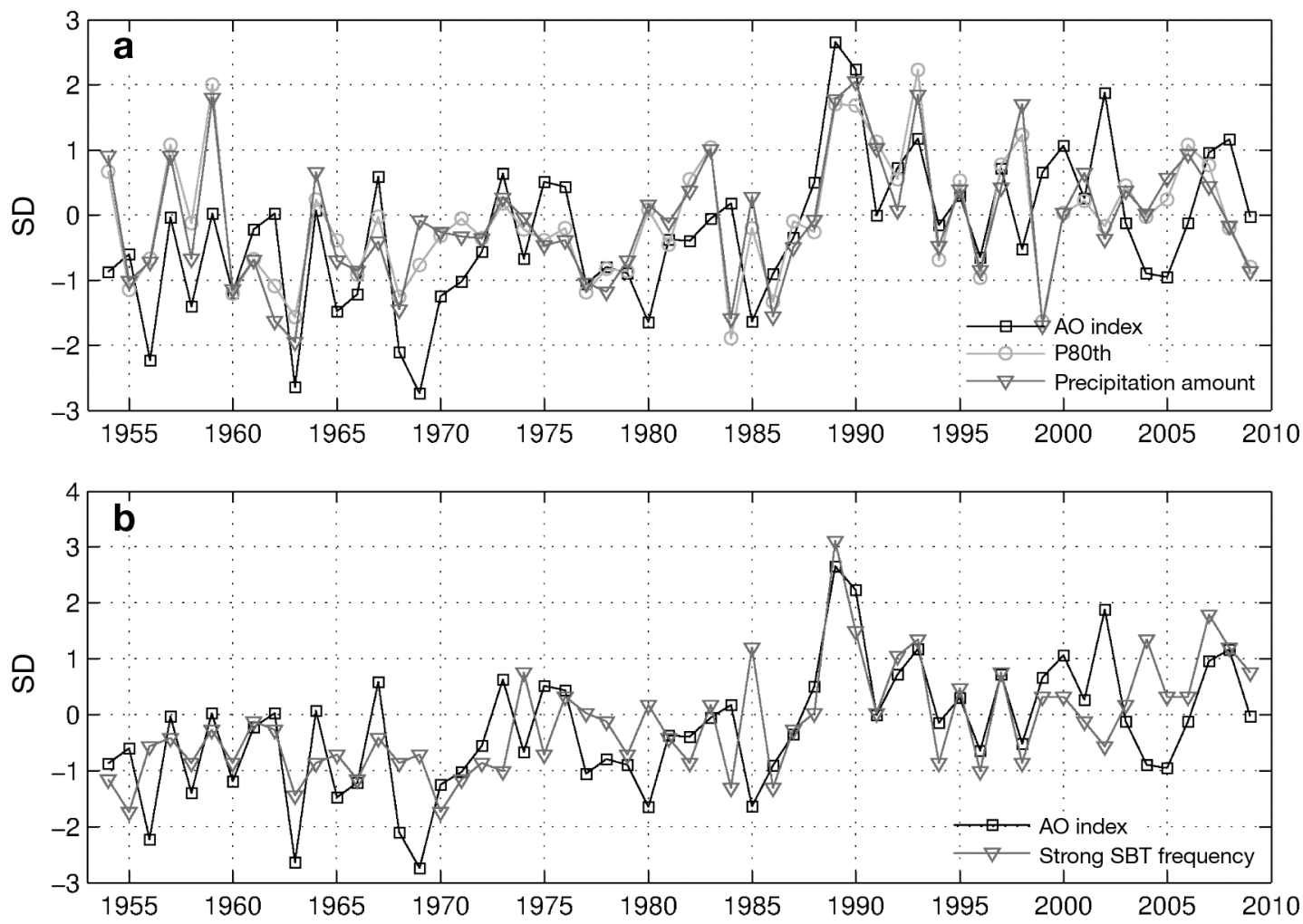

Fig. 3. (a) Standard deviation (SD) of time series of Arctic Oscillation (AO) index and frequency of extreme precipitation (P80th) and precipitation amount over central-southern China during January to February. (b) SD of time series of the frequency of a strong southern branch trough (SBT) and the AO index during January to February. All the time series are standardized with respect to the reference period 1971-2000

out the long-term trends of both time series, the correlation is 0.28 , significant at the $95 \%$ confidence level. The significant relationship between $\mathrm{AO}$ and precipitation over central-southern China provides additional support for the significance of the AOP80th relationship.

\subsection{Comparison of AO- and ENSO-related precipitation changes}

Winter climates over East Asia could be affected by both AO and ENSO. To determine if the AOprecipitation relationship (analyzed in Section 3.1) distorted the ENSO signal, we compared AOrelated precipitation anomalies and ENSO-related precipitation anomalies, with reference to both extreme precipitation frequency and precipitation amount.

To estimate the precipitation anomalies solely associated with the $\mathrm{AO}$, the 2 time series of precipitation and $\mathrm{AO}$ index for each station were regressed onto the ENSO index, and then the 2 residuals are sub- jected to correlation analysis (for details see the Section 2.2). Fig. 4a presents the spatial distribution of the correlation between $\mathrm{AO}$ and P80th, which is obtained by excluding the ENSO-related components from their original time series. Significant positive correlations occur over a wide area of China. Of all 287 stations, 226 stations have positive correlations and $94(114)$ stations are positively significant at the $95 \%(90 \%)$ confidence level. The significant stations are mainly located over central-southern China. The correlation between the $\mathrm{AO}$ and the P80th, averaged over the China (central-southern China) is $0.43(0.45)$, which in both cases is significant at the $99 \%$ confidence level (Table 1). We also examined the precipitation amount anomalies solely associated with the AO (figure not shown). Similarly, positive correlations prevail over China and stations with significantly positive correlation are centered over centralsouthern China. Among 287 stations, 234 stations have positive correlations and 107 (122) stations are positively significant at the $95 \%(90 \%)$ confidence level. The correlation between regional mean precipitation amount over China (central-southern China) 

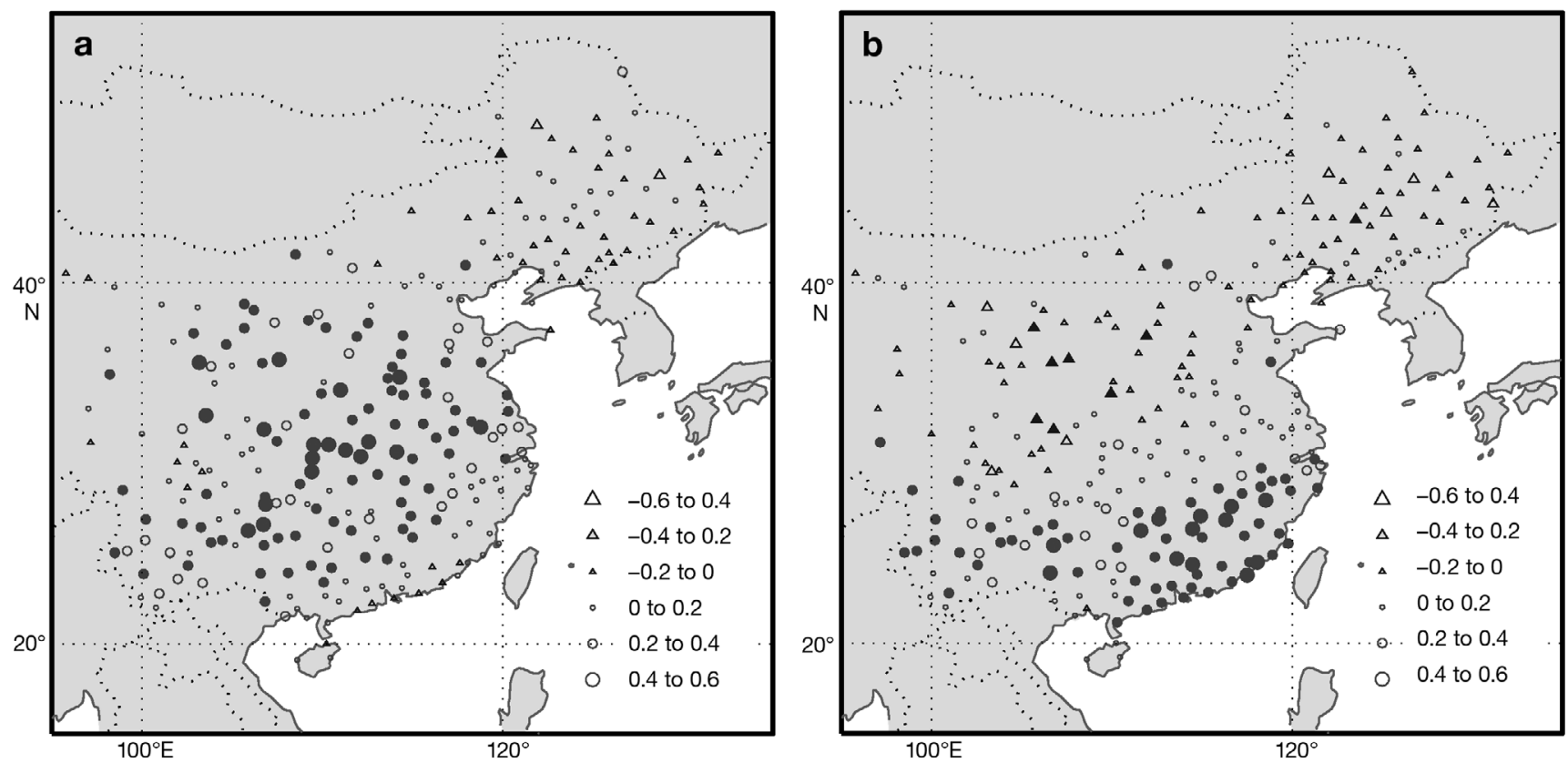

Fig. 4. Correlation (R-values) between frequency of extreme precipitation (P80th) and (a) Arctic Oscillation (AO) and (b) Niño 3.4 SST in January to February. Triangles: negative values; circles: positive values. Filled circles (triangles): positive (negative) correlations above $95 \%$ confidence level. In (a) the correlation is obtained by excluding the ENSO-related components from the time series, and in (b) by excluding the AO-related components

and the $\mathrm{AO}$ is $0.38(0.50)$, which in both cases is significant at the $99 \%$ confidence level (Table 1). The precipitation amount anomalies solely associated with the $\mathrm{AO}$ are consistent with the P80th anomalies solely associated with the AO. When compared with the AO-precipitation correlation obtained from the original time series (Fig. 2a), when the ENSOrelated components from original time series there are more stations with a significantly positive AOprecipitation correlation, especially over centralsouthern China, and more stations with higher correlation coefficient.

Following the same procedure, the precipitation anomalies solely associated with the ENSO were examined. For each station, the 2 original time series of precipitation and the ENSO index were regressed onto the AO index. The 2 residuals of the original time series minus the regression estimation were regarded as the AO-free components and subjected to correlation analysis. Fig. 4b shows the spatial pattern of correlation between ENSO and P80th, which is obtained by excluding the AO-related components from both original time series. As shown in the figure, in association with positive Niño 3.4 SST, the P80th increases significantly over the southern coastal regions of China, but decreases moderately over central and northeastern China. We constructed an average time series of P80th over the southern coast region (approximately $22^{\circ}-28^{\circ} \mathrm{N}$ and $100^{\circ}-120^{\circ} \mathrm{E}$ ) and compared this with the Niño 3.4 SST time series. After excluding the AO-related components from the original time series, the correlation between the ENSO index and regional mean P80th is 0.43 , significant above the $99 \%$ confidence level.The precipitation amount anomalies solely associated with the ENSO were also examined. The results are almost identical to the P80th, with significantly positive correlations in southern regions and insignificantly negative correlations in central and northeastern China (not shown). When the AO-related components are excluded from the original time series, the correlation between the ENSO index and the regional mean precipitation over the southern coast region is 0.43 , significant above the $99 \%$ confidence level.

Thus differences between effects of the $\mathrm{AO}$ and the ENSO phases can be clearly identified. The principal difference between the AO-precipitation relationship and ENSO-precipitation relationship is in the spatial distribution of the associated precipitation anomalies. The AO shows much stronger connection to precipitation amount and the extreme precipitation frequency over central-southern China, while the effect of the ENSO on both variables is more significant over the southern coastal region. This difference might be related to different physical processes involved in the precipitation linkages. 


\section{CHANGES IN ATMOSPHERIC CIRCULATION AND WATER VAPOR TRANSPORT}

\subsection{Lower to middle troposphere}

In order to investigate the dominant atmospheric circulation changes in association with the $\mathrm{AO}-$ precipitation links, we performed regression analysis of simultaneous anomalies in the low-level and middle-level tropospheric atmosphere. The analyzed variables were horizontal winds at $700 \mathrm{hPa}$ level and geopotential height at $500 \mathrm{hPa}$ level (H500). Note that the ENSO-precipitation correlations over centralsouthern China are quite weak, as shown in the previous section. Hence, for simplicity, when investigating AO-related atmospheric circulation changes and water vapor transport, we used the original time series (not considering the possible influence of the ENSO signal) to obtain the results presented in the following sections.
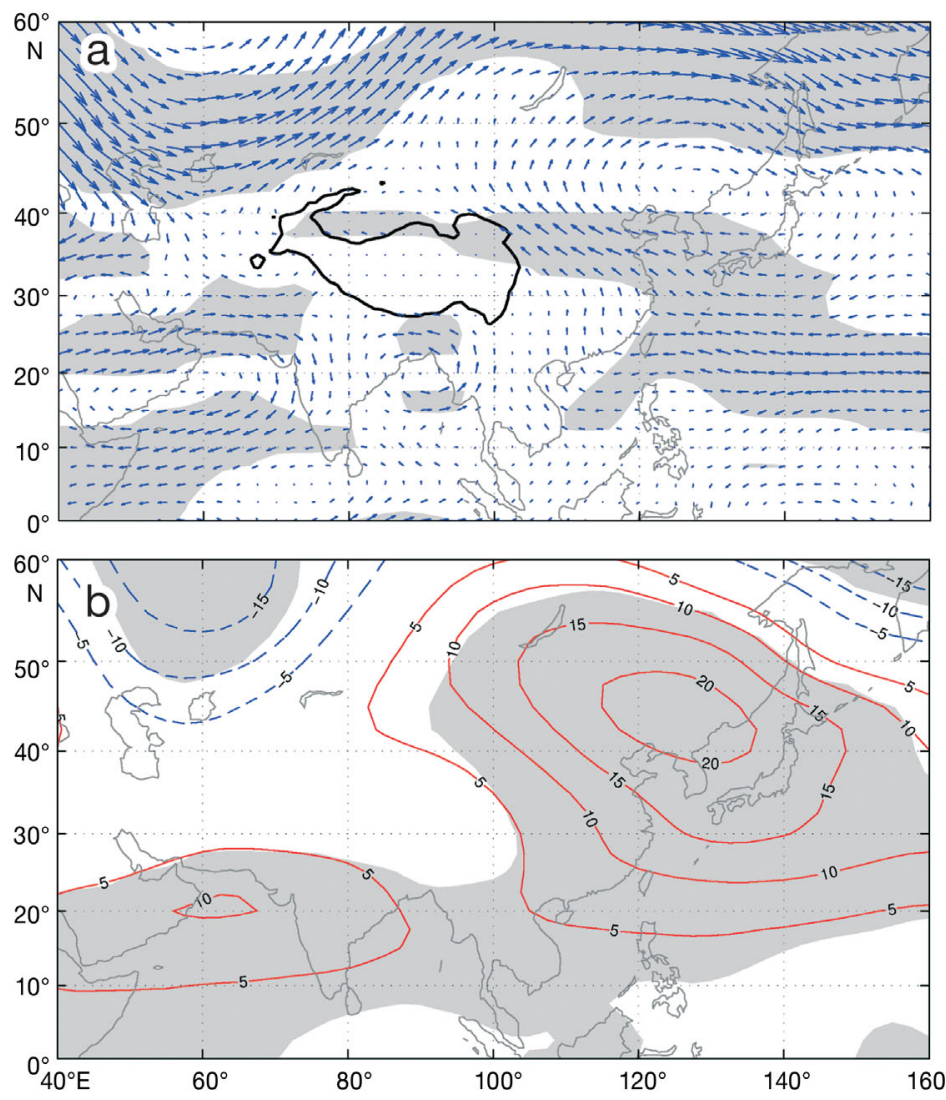

Fig. 5a shows the regression coefficients of horizontal winds at the $700 \mathrm{hPa}$ level against the AO index. When the AO is in a positive phase, the wind anomaly pattern is characterized by 4 distinct anomalous centers: 2 anticyclonic anomalies appearing over the northeast Asia $\left(35^{\circ}-55^{\circ} \mathrm{N}\right.$ and $\left.110^{\circ}-140^{\circ} \mathrm{E}\right)$ and the Arabian Sea $\left(10^{\circ}-25^{\circ} \mathrm{N}\right.$ and $\left.40^{\circ}-70^{\circ} \mathrm{E}\right)$ and $2 \mathrm{cy}-$ clonic anomalies over the western Siberia $\left(40^{\circ}-60^{\circ} \mathrm{N}\right.$ and $40^{\circ}-80^{\circ} \mathrm{E}$ ) and the Bay of Bengal (BOB; $15^{\circ}-$ $25^{\circ} \mathrm{N}$ and $80^{\circ}-100^{\circ} \mathrm{E}$ ). At the same time, significantly anomalous southerly winds prevail across the south of China, especially central-southern China. These significant southerly wind anomalies over centralsouthern China may cause extreme precipitation events and increased precipitation amounts. These anomalous southerlies are likely linked to the configuration of the cyclonic anomaly over the BOB and the anticyclonic anomaly over northeast Asia. More importantly, the cyclonic circulation over the BOB is surely a sign of the frequent activity of the southern
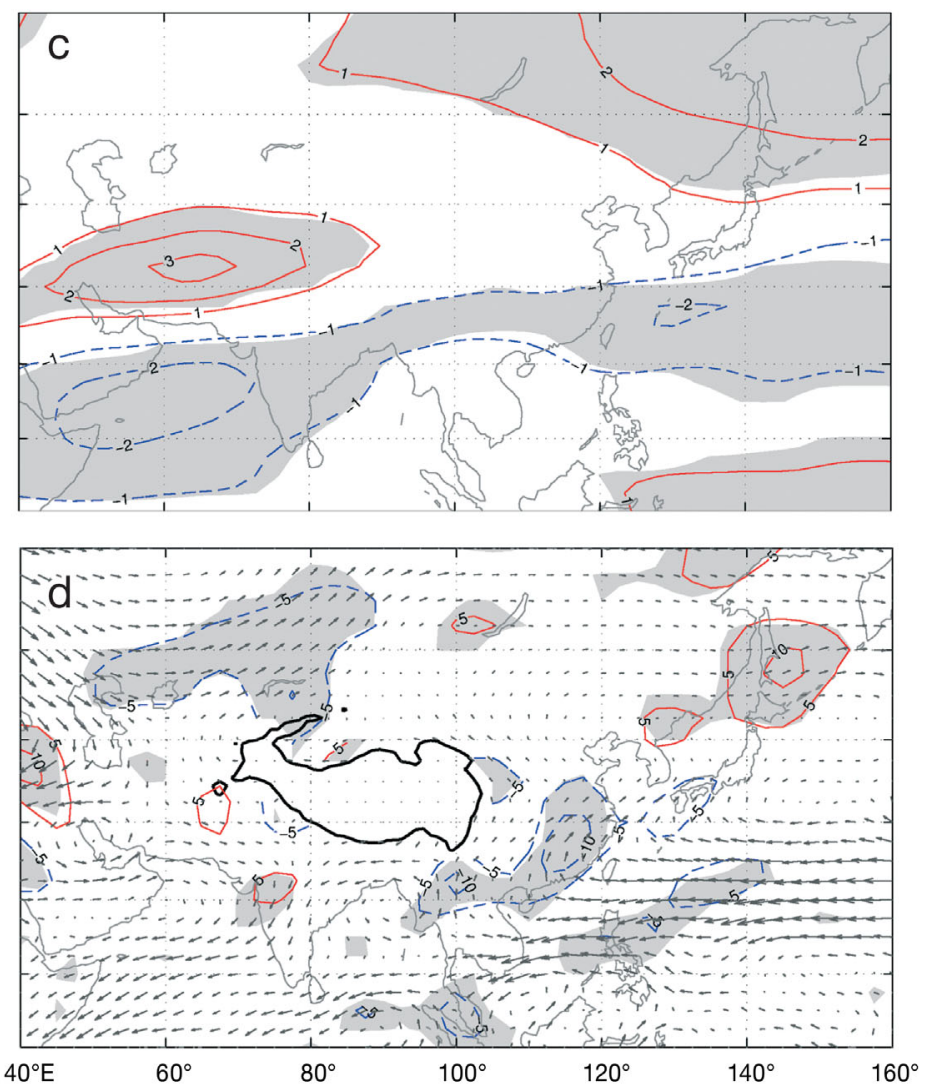

Fig. 5. Regression of variables against 1 standard deviation of the Arctic Oscillation (AO) index, January to February: (a) horizontal winds at $700 \mathrm{hPa}$ level $\left(\mathrm{m} \mathrm{s}^{-1}\right)$, (b) geopotential height (m) at $500 \mathrm{hPa}$ level, (c) zonal wind ( $\mathrm{m} \mathrm{s}^{-1}$ ) at $200 \mathrm{hPa}$ level, (d) water vapor flux $\left(\mathrm{kg} \mathrm{m}^{-1} \mathrm{~s}^{-1}\right)$ from the surface to $300 \mathrm{hPa}$ (vectors) and vertical velocity $\left(0.001 \mathrm{pa} \mathrm{s}^{-1}\right)$ averaged between 700 and $500 \mathrm{hPa}$ (contour lines). The maximum length of the vectors is equivalent to $1.90 \mathrm{~m} \mathrm{~s}^{-1}$ in (a) and $27.7 \mathrm{~kg} \mathrm{~m}^{-1} \mathrm{~s}^{-1}$ in (d). In (b-d), solid lines represent positive values and dashed lines negative values. Shaded areas: extent of positive correlation above $95 \%$ confidence level. The heavy solid line in (a) and (d) encloses the Tibetan Plateau and the values in this region have been removed 
branch trough (SBT, also called India-Burma trough) over the BOB. The SBT, which is mostly apparent at $700 \mathrm{hPa}$ level, is the most favorable synoptic system for the formation of precipitation over southern China during wintertime (Suo \& Ding 2009). Many previous studies indicated that a more active SBT may enhance synoptic scale disturbances in vertical motion and moisture supply from the BOB to centralsouthern China (e.g. Gao \& Yang 2009, Bao et al. 2010) and these in turn likely contribute to increased precipitation and the occurrence of extreme precipitation events over central-southern China.

We subsequently analyzed H500 anomalies in the middle troposphere associated with the positive AO phase. As seen in Fig. 5b, a positive AO phase is related to 3 significant height anomalies in the middle troposphere: 2 positive height anomalies, over northeast Asia $\left(35^{\circ}-55^{\circ} \mathrm{N}\right.$ and $\left.110^{\circ}-140^{\circ} \mathrm{E}\right)$ and the Arabian Sea $\left(10^{\circ}-25^{\circ} \mathrm{N}\right.$ and $\left.40^{\circ}-70^{\circ} \mathrm{E}\right)$, and a negative anomaly over western Siberia $\left(40^{\circ}-60^{\circ} \mathrm{N}\right.$ and $40^{\circ}-$ $80^{\circ} \mathrm{E}$ ). The positive height anomaly over northeast Asia indicates a weak East Asian trough, while the negative height anomaly over western Siberia shows a weak Ural high. These changes in the East Asian trough and the Ural high imply a weak East Asian winter monsoon, which is consistent with the southeasterly anomalies across northern China to Mongolia in the lower troposphere, as shown in Fig. 5a. The weaker winter monsoon in the East Asia provides favorable conditions for anomalous northward transport of warm and moist air from the BOB and southern China to central China. Therefore, both the anomalous southerly wind across central-southern China and the weaker winter monsoon in China will favor the occurrence of extreme precipitation events and increased precipitation over central-southern China.

\subsection{Upper troposphere}

To identify anomalies in the upper troposphere associated with $\mathrm{AO}$ changes, we regressed the zonal wind at $200 \mathrm{hPa}$ level (U200) onto the AO index. As shown in Fig. $5 \mathrm{c}$, during a positive $\mathrm{AO}$ phase there are 2 bands of positive anomaly: to the north of northeastern China $\left(50^{\circ}-60^{\circ} \mathrm{N}\right.$ and $\left.100^{\circ}-160^{\circ} \mathrm{E}\right)$ and over West Asia $\left(25^{\circ}-40^{\circ} \mathrm{N}\right.$ and $\left.40^{\circ}-80^{\circ} \mathrm{E}\right)$. At the same time, there is an extensive belt of negative anomaly, stretching from the Arabian Sea $\left(10^{\circ}-25^{\circ} \mathrm{N}\right.$ and $\left.40^{\circ}-70^{\circ} \mathrm{E}\right)$ to the region to the south of Japan, with centers both over the Arabian Sea and the region to the south of Japan. These anomalies are significant above the $95 \%$ confidence level. The negative anomaly to the south of Japan indicates a weak East Asian jet stream, and the positive anomaly over the West Asia $\left(25^{\circ}-\right.$ $40^{\circ} \mathrm{N}$ and $40^{\circ}-80^{\circ} \mathrm{E}$ ) implies a strong Middle East jet stream (MEJS). Many previous studies (e.g. Gao \& Yang 2009, Wen et al. 2009) have emphasized the influences of upper tropospheric jet streams, such as the MEJS, on precipitation anomalies over central-southern China. The intensified MEJS strengthens the trough embedded in the southern branch of the subtropical westerlies over the southern flank of Tibetan Plateau (Wen et al. 2009), thus bringing more water vapor from the BOB to eastern China (see Fig. 5d). Following Yang et al. (2004), we defined an index of MEJS as U200 at $20^{\circ}-30^{\circ} \mathrm{N}$ and $40^{\circ}-70^{\circ} \mathrm{E}$ minus U200 at $30^{\circ}-40^{\circ} \mathrm{N}$ and $15^{\circ}-45^{\circ} \mathrm{E}$. The correlation between the MEJS and the P80th over central-southern China is 0.43 , significant at the $99 \%$ confidence level. Meanwhile, the AO-MEJS correlation is 0.36 , significant above the $99 \%$ confidence level. The significant correlations among the AO, the MEJS index, and the P80th over central-southern China provide additional evidence that the MEJS might be a factor in connecting $\mathrm{AO}$ and precipitation over central-southern China.

\subsection{Water vapor transport}

We computed the regression of water vapor transport onto the AO index. As seen in Fig. 5d, in a positive AO phase, water vapor fluxes are characterized by a cyclonic anomaly over the $\mathrm{BOB}$, a southwesterly anomaly over the south of China, a large area of easterly anomaly to the south of Japan $\left(15^{\circ}-30^{\circ} \mathrm{N}\right.$ and $120^{\circ}-160^{\circ} \mathrm{E}$ ), and an anticyclonic anomaly over the Arabian Sea $\left(10^{\circ}-25^{\circ} \mathrm{N}\right.$ and $\left.40^{\circ}-70^{\circ} \mathrm{E}\right)$. All these anomalies are significant at the $90 \%$ confidence level. The southwesterly anomalies of water vapor flux over the south of China, especially over centralsouthern China, which favor increased precipitation amounts and the more frequent occurrence of extreme precipitation events, are consistent with the southerly wind anomalies in the lower troposphere (see Fig. 5a). Note that the southwesterly anomalies of water vapor flux over central-southern China are likely caused by the cyclonic water vapor flux anomaly over the BOB and the large area of easterly water vapor flux anomaly to the south of Japan $\left(15^{\circ}-30^{\circ} \mathrm{N}\right.$ and $120^{\circ}-160^{\circ} \mathrm{E}$ ). The cyclonic anomaly of water vapor flux over the BOB is associated with frequent SBT activities there. When the SBT activity over the $\mathrm{BOB}$ strengthens in association with a positive $\mathrm{AO}$ phase, it initiates the cyclonic water vapor flux anomaly and conducts large amounts of water vapor fur- 
ther north than normal to the south of China. At the same time, the large area of easterly water vapor flux anomaly to the south of Japan may be caused by the geopotential height anomaly in the middle troposphere shown in Fig. 5b over northeast Asia. The easterly water vapor flux anomaly to the south of Japan would enhance moisture transport from the Pacific to central-southern China and thus help induce more precipitation extremes over central-southern China.

In addition, we analyzed the variation of vertical air motions (represented by omega values averaged between $700 \mathrm{hPa}$ and $500 \mathrm{hPa}$ ) associated with $\mathrm{AO}$ change (Fig. 5d). Negative (positive) omega values indicate ascending (descending) motions, which are denoted by dashed (solid) lines in the Fig. 5d. As seen in the figure, when $\mathrm{AO}$ is in a positive phase, a significant enhancement of ascending motion appears from the east of the BOB to central-southern China. The changes over these regions are significant at the $95 \%$ confidence level. This evident enhancement of ascending motions over the south of China may be caused by increased SBT activities over the BOB. The enhancement of SBT activity not only enhances water vapor transport from the BOB to central-southern China, but also initiates ascending motions over the south of China (Suo \& Ding, 2009). Therefore, the SBT over the BOB may be an important factor leading to the occurrence of extreme precipitation over central-southern China.

Overall, the configuration of ascending motion and increased water vapor transport over central-southern China in association with a positive AO phase enhances the possibility of occurrence of extreme precipitation events over central-southern China. During this process, increased SBT activity plays a role in initiating ascending motions; at the same time, the easterly water vapor flux anomaly to the south of Japan produces the increased water vapor transport.

\section{CHANGES IN SYNOPTIC SCALE DISTURBANCES}

\subsection{Disturbances in meridional wind}

Changes in monthly and seasonal circulation, as described above, underpin the AO-P80th relationship over central-southern China, and provide the climate background for the occurrence of extreme events. But weather activity on the synoptic scale is the direct cause of extreme precipitation events. Therefore, in order to further elucidate the AOP80th relationship, an examination of AO-related changes in weather activity on the synoptic scale is required. To this end, we examined synoptic scale disturbances, i.e. high-frequency variations in meridional wind and omega values.

We first examined AO-related changes in the frequency of strong meridional wind. The frequency of strong meridional wind is set by percentiles calculated from data on daily meridional wind at $700 \mathrm{hPa}$ level (V700) as follows. (1) Data on daily climatological V700 during January to February are obtained for the reference period of 1971-2000. (2) The climatological V700 determines the threshold value; for a given grid point, when the climatological V700 is southerly (northerly), the threshold value is the 80th (20th) percentile of daily V700 during January to February in 1971-2000. (3) For the grid point with southerly (northerly) climatological V700, the number of days with daily V700 exceeding (below) the threshold during January to February is counted year by year, and finally (4) this yields a time series of the frequency of strong meridional wind.

We applied a regression analysis of strong meridional wind frequency against AO index. Results are shown in Fig. 6. During a positive AO phase, there are higher frequencies of strong southerly wind from the east BOB to southern China and higher frequencies of strong northerly wind over the west BOB. This implies that positive AO winters tend to be accompanied by frequent strong SBT activities. The enhanced strong SBT activity favors precipitation over centralsouthern China. At the same time, when the AO is in a positive phase, there is a reduced frequency of strong northerly wind across Mongolia and northern China. This indicates that the East Asian trough has shifted eastward, causing a cold monsoonal flow, moving eastward off the continent. As a result, moist air can be transported much further north into central-southern China, which brings increased precipitation amounts as well as inducing extreme precipitation events, as described in Section 4.1.

As analyzed above, the SBT is an important circulation system for initiating precipitation over centralsouthern China. On synoptic time scales, the SBT appears as a transient trough, or cyclone, or low pressure system. To determine synoptic SBT activity, we defined a daily SBT index. An active SBT generally has a persistent strong meridional shear in V700 (Suo \& Ding 2009), hence we divided the domain of climatological SBT into 2 regions, namely, region 1 $\left(80^{\circ}-90^{\circ} \mathrm{E}\right.$ and $\left.15^{\circ}-25^{\circ} \mathrm{N}\right)$ and region $2\left(90^{\circ}-100^{\circ} \mathrm{E}\right.$ and $15^{\circ}-25^{\circ} \mathrm{N}$ ), and used the difference in daily V700 averaged across both regions (region 2 minus region 1) as the daily SBT index. A high index indicates a larger difference, and corresponds to stronger SBT 


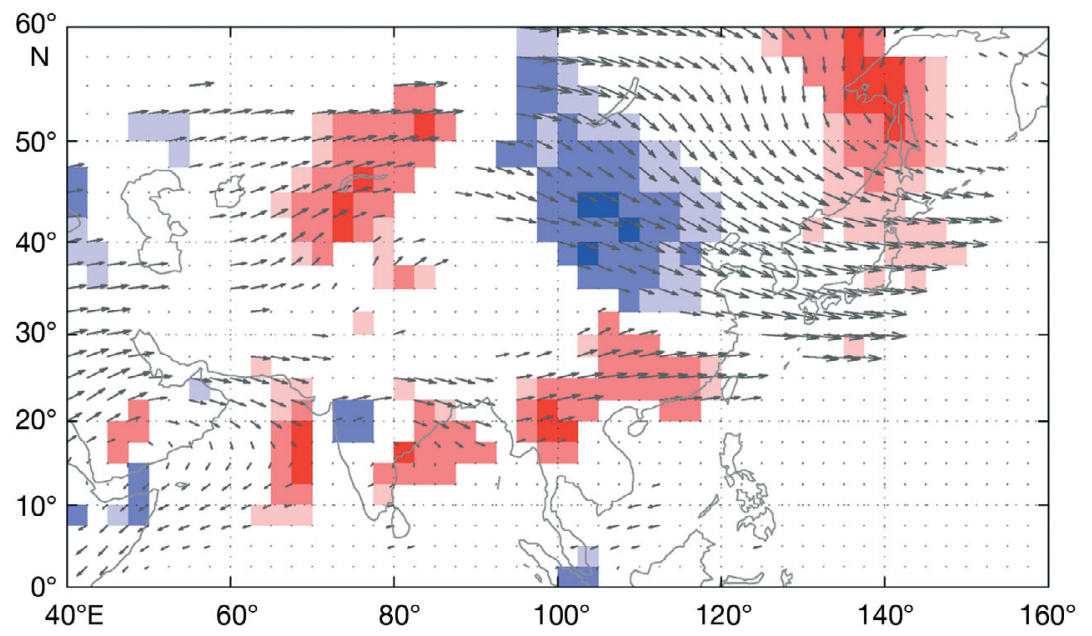

Fig. 6. Regression of frequencies of strong meridional wind against 1 standard deviation of the Arctic Oscillation (AO) index. The vectors show climatological horizontal winds at the $700 \mathrm{hPa}$ level in January-February during 1954-2009. For clarity, only vectors whose meridional component exceeds $1 \mathrm{~m} \mathrm{~s}^{-1}$ are shown. The longest vector is equivalent to $20.5 \mathrm{~m} \mathrm{~s}^{-1}$. The red and blue shadings represent positive and negative regression coefficients, respectively, and the light, moderate, and heavy shadings indicate absolute values exceeding 1 , 2 , and 3, respectively. For instance, in a specific grid square, when its climatological meridional wind is southerly (northerly), the regression coefficient indicates the anomaly in the frequency of strong southerly (northerly) winds against 1 standard deviation of the $\mathrm{AO}$ index

activity. Because extreme precipitation over centralsouthern China during winter is normally caused by strong SBT activities, we defined a measure of strong SBT frequency and analyzed the relationships among strong SBT frequency, the AO and the P80th over central-southern China. Strong SBT frequency is defined by percentiles based on the daily SBT index. The threshold value for computing strong SBT frequency is set as the 80th percentile of the daily SBT index during January to February in the reference period 1971-2000. The number of days with a daily SBT index exceeding the threshold value during January to February is counted year by year and this yields the time series of strong SBT frequency during 1954-2009. The time series of the AO index is obtained by averaging AO index in January to February during 19542009. The time series of strong SBT frequency and the AO index are plotted together for comparison in Fig. 3b. As seen in the figure, both time series cochange consistently with an in-phase relationship. The correlation between them is 0.55 , significant above the $99 \%$ confidence level. After excluding the ENSO-related components from the original time series, the correlation remains 0.55 , still significant at the $99 \%$ confidence level (Table 1). Meanwhile, the correlation between strong SBT frequency and the P80th averaged over central-southern China is 0.51, significant above the $99 \%$ confidence level. After excluding ENSO-related components from the original time series, the correlation becomes 0.58 , also significant at the $99 \%$ confidence level. These high correlations suggest that a positive AO phase is accompanied by frequent strong SBT activity, which is related to the occurrence of extreme precipitation events.

Finally, we checked the frequency distribution of daily SBT in detail. We selected 5 years with the highest AO indices $(1989,1990,1993,2002$, and 2008), and compared these to the 5 years with the lowest $\mathrm{AO}$ indices (1956, 1963, 1965, 1968, and 1969). Results show that the frequency of daily SBT in these years has a quasi-normal distribution. During the positive AO years, the mean and variance of daily SBT index are $3.8 \mathrm{~m} \mathrm{~s}^{-1}$ and $11.66 \mathrm{~m}^{2}$ $\mathrm{s}^{-2}$, respectively; by contrast, during the negative AO years SBT index values are $1.9 \mathrm{~m} \mathrm{~s}^{-1}$ and $7.76 \mathrm{~m}^{2} \mathrm{~s}^{-2}$ for mean and variance, respectively. It is evident that, compared to the negative AO years, the positive AO years are accompanied by decreased frequency of low SBT index values and increased frequency of high SBT index values (Fig. 7). Based on the frequency distribution, we estimated the percentage of the SBT extremes in daily indices, and then compared these percentages across positive and negative AO years. During the positive AO years, extreme SBT values account for nearly $35 \%$ of all days. But the percentage drops remarkably to only $10 \%$ during the negative AO years. This comparison is consistent with the significant positive correlation between the AO and strong SBT frequency. Thus, the

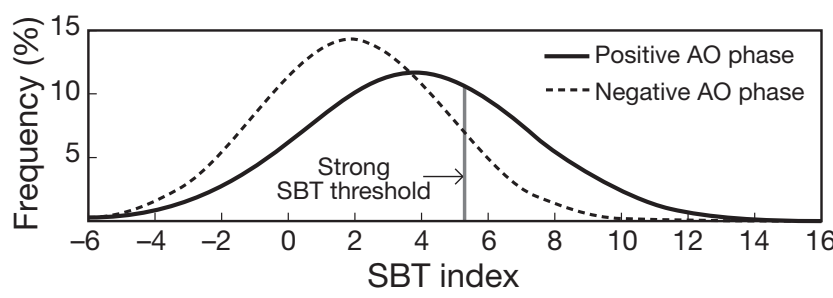

Fig. 7. Composite of daily southern branch trough (SBT) index during positive and negative Arctic Oscillation (AO) phases. Vertical solid line: threshold of strong SBT. The threshold is determined as the value of the 80th percentile of the daily SBT index for the reference period 1971-2000. Note that the probability density function curve of the daily SBT index is smoothed 
positive AO phase tends to be accompanied by a marked increase in strong SBT events. This increases precipitation and the frequency of extreme precipitation events over central-southern China.

\subsection{Disturbances in vertical motion}

In order to better understand AO-related changes in large scale vertical motions, which play an important role during extreme precipitation, we analyzed AO-related synoptic scale disturbances in vertical motion. These are represented in the form $\sqrt{W^{\prime 2}}$, where the $w$ indicates the omega value, the prime indicates the anomalies resulting from high-pass filtering and the bar indicates the mean during January to February. The typical timescale of weather activity is about $7 d_{\text {; }}$ therefore, we applied a high-pass filter to remove the components longer than $7 \mathrm{~d}$. Then the synoptic scale variance was calculated locally for January to February, from omega variances averaged between 700 and $500 \mathrm{hPa}$ levels. Fig. 8a shows the correlation between synoptic scale disturbances in vertical motion and AO. Positive correlations span a band along the southern flank of the westerly flow with centers in West Asia $\left(25^{\circ}-40^{\circ} \mathrm{N}\right.$ and $\left.40^{\circ}-70^{\circ} \mathrm{E}\right)$, northern Indian $\left(20^{\circ}-30^{\circ} \mathrm{N}\right.$
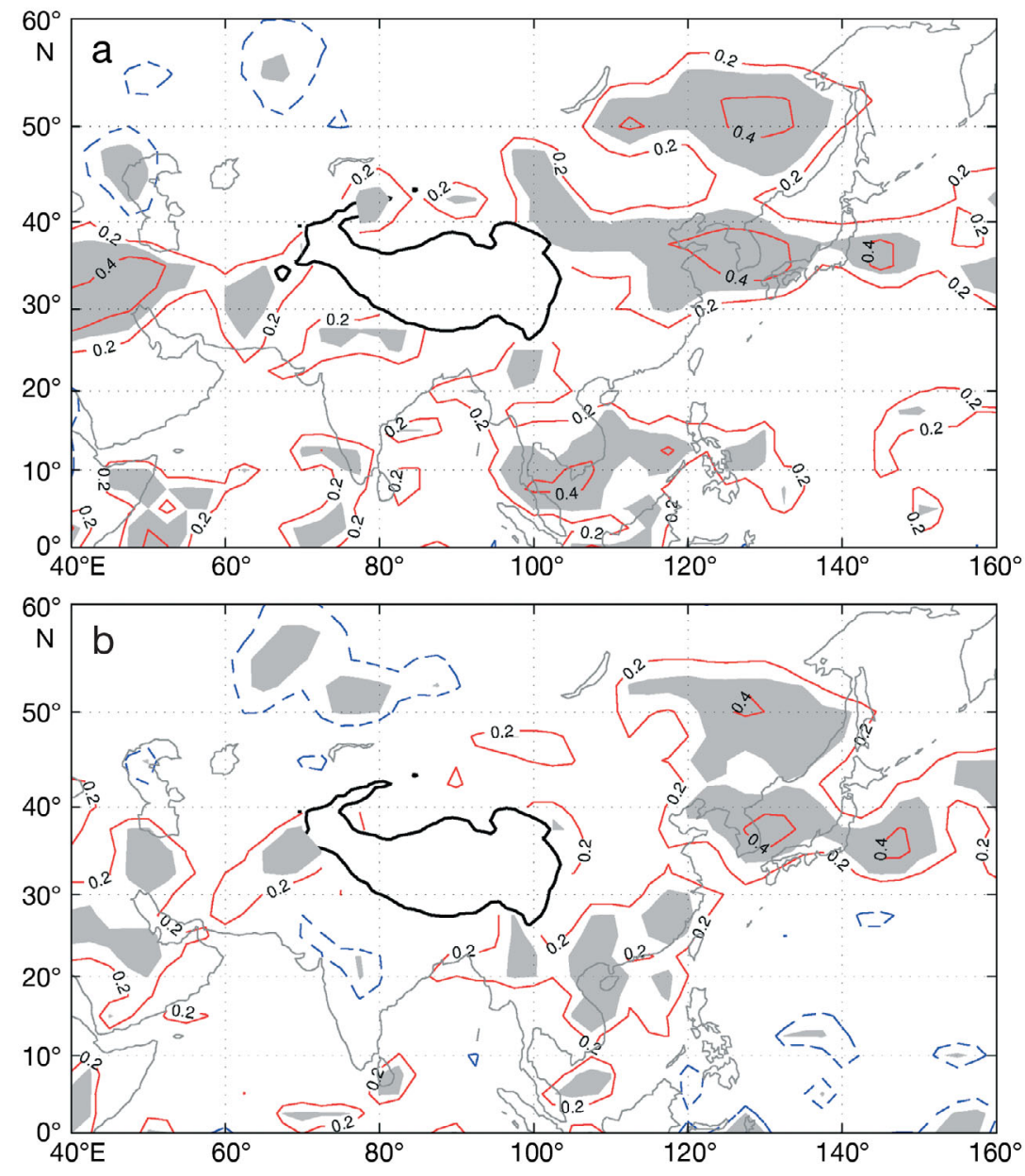

Fig. 8. Correlation (R-values) between Arctic Oscillation (AO) and (a) synoptic scale disturbances between $700 \mathrm{hPa}$ and $500 \mathrm{hPa}$ and (b) frequency of extreme precipitation (P80th) over central-southern China. Solid lines: positive values; dashed lines: negative values. Shaded areas: extent of positive correlation above $95 \%$ confidence level. The heavy solid line encloses the Tibetan Plateau and the values in this region have been removed

and $\left.70^{\circ}-85^{\circ} \mathrm{E}\right)$, and Myanmar $\left(15^{\circ}-25^{\circ} \mathrm{N}\right.$ and $90^{\circ}-$ $\left.100^{\circ} \mathrm{E}\right)$. Positive correlations also occur over northeast Asia $\left(30^{\circ}-55^{\circ} \mathrm{N}\right.$ and $\left.100^{\circ}-140^{\circ} \mathrm{E}\right)$. This belt of positive correlation from the West Asia $\left(25^{\circ}-40^{\circ} \mathrm{N}\right.$ and $40^{\circ}-$ $\left.70^{\circ} \mathrm{E}\right)$ to Myanmar $\left(15^{\circ}-25^{\circ} \mathrm{N}\right.$ and $\left.90^{\circ}-100^{\circ} \mathrm{E}\right)$ is apparently the track of the MEJS along the southern Tibetan Plateau. It suggests that the MEJS may be an important factor for the enhancement of weather activity over the BOB during a positive AO phase. The enhanced SBT and synoptic activity over the BOB and southern China is not a local phenomenon but a large scale one that occurs in conjunction with the AOrelated westerly jet stream variations.

In addition, we investigated the correlation between synoptic scale disturbances in vertical motion and the P80th over central-southern China (Fig. 8b). In association with the increased P80th over central- southern China, synoptic scale disturbances in vertical motion increase over West Asia $\left(25^{\circ}-40^{\circ} \mathrm{N}\right.$ and $\left.40^{\circ}-70^{\circ} \mathrm{E}\right), \quad$ Myanmar $\left(15^{\circ}-25^{\circ} \mathrm{N}\right.$ and $\left.90^{\circ}-100^{\circ} \mathrm{E}\right)$, southern China $\left(10^{\circ}-30^{\circ} \mathrm{N}\right.$ and $\left.100^{\circ}-120^{\circ} \mathrm{E}\right)$, and northeast Asia $\left(30^{\circ}-55^{\circ} \mathrm{N}\right.$ and $\left.100^{\circ}-140^{\circ} \mathrm{E}\right)$. Clearly, the regional precipitation extremes in central-southern China may be associated with the synoptic scale disturbances in vertical motion. Interestingly, the west-east oriented correlation from the BOB to the south of China, together with the simultaneous high correlation over the West Asia, again suggest the importance of the transient variations along the MEJS and the southern branch of the westerlies over the southern flank of the Tibetan Plateau. Therefore, it can be concluded that a positive AO phase may be accompanied by an intensified MEJS and SBT, which could enhance synoptic activities over the north of 
the BOB and central-southern China. The enhanced disturbances in vertical air motion increase precipitation amounts and lead to the more frequent occurrence of extreme precipitation events over central-southern China.

\section{DISCUSSION}

The results above indicate that the AO has a statistical relationship with the frequency of extreme precipitation events over central-southern China during January to February. However, some issues that should be discussed are: (1) whether this relationship is stable across different periods; (2) whether this relationship depends on the phases of solar activity; (3) whether this relationship is caused by the fact that the AO may be driving the precipitation amount as a whole and not specifically extreme precipitation events; and (4) what mechanism could account for the link between AO, MEJS and SBT.

We addressed each of these questions in turn in the following paragraphs. Firstly, we calculated the correlation between the $\mathrm{AO}$ and the P80th for each station for 2 different periods, i.e. 1954 to 1981 and 1982 to 2009 (figure not shown). Results show that during both periods, the majority of stations show an inphase relationship between the AO and the P80th, and that stations with significantly positive correlations mainly occur over central-southern China. This pattern is similar to that obtained from the data covering the whole period 1954-2009 (see Fig. 2a), although there are slightly fewer stations with significantly positive correlations when data from the 2 periods are analyzed separately. Thus, the AOrelated changes in the frequency of extreme precipitation are stable.

Secondly, we examined whether the AO-P80th relationship depends on the phases of solar activity during winter. Recently some studies have indicated that solar cycle phase may modify the influence of the North Atlantic Oscillation (NAO) on the wintertime climate (e.g. Gimeno et al. 2003). For solar maximum phases, AO and northern hemisphere temperatures are positively correlated, but for solar minimum phases correlations are not significant or even negative. We used monthly mean values of the $10.7 \mathrm{~cm}$ solar radio flux during January to February to represent the winter solar cycle phase. The solar radio flux data was downloaded from National Geophysical Data Center, NOAA (www.ngdc.noaa.gov/stp/solar/ solardataservices.html). Based on this dataset, we selected 25 high solar activity winters and 31 low solar activity winters, defined by whether the solar radio flux was higher or lower than the average. Then we computed the correlations between the AO and the P80th averaged over the central-southern China during high and low solar activity years, respectively, and compared them to the correlation derived by whole data during 1954-2009. Results show that during the high solar activity winters, the correlation is increased with a correlation coefficient of 0.56. By contrast, during the low solar activity winters, the correlation is decreased with a correlation coefficient of 0.32 . These correlations are both significant at the $99 \%$ confidence level. However this result suggest that the AO-related anomalies in the frequency of extreme precipitation over the centralsouthern China may be enhanced during solar maximum phases.

Since the spatial distribution of correlation between P80th and AO is not different from that of the correlation between precipitation amount and $\mathrm{AO}$, this would indicate that the AO may be driving the distribution of precipitation amount as a whole and not specifically the occurrence of extreme precipitation events. To examine this possibility, we thirdly calculated the probability distribution of daily precipitation amounts in January to February during AO extreme years, i.e. the 5 years with the highest and 5 years with the lowest AO indices listed in Section 5.1 (data not shown). We found that there are 2 different types of probability distribution of daily precipitation amount during the AO extreme years. When all stations in China are considered, the curve of probability distribution function (pdf) during the positive AO phase is shifted to the right as a whole compared with the curve of pdf during the negative AO phase. This means that the AO may be driving the precipitation distribution as a whole and consequently increases the frequency of extreme precipitation events. However, when only stations in central-southern China are considered, the curve of pdf is skewed; the probability of precipitation amounts between $3 \mathrm{~mm}$ and $10 \mathrm{~mm}$ is higher in the positive AO phase than in the negative AO phase, and the probability of precipitation amounts $<3 \mathrm{~mm}$ is not changed during the $\mathrm{AO}$ extreme years. The above analysis implies that in central-southern China, the AO may influence the occurrence of extreme precipitation events, rather than overall precipitation events.

Finally, a causal mechanism has been proposed linking the AO to MEJS and SBT through a wave train bridge. Fig. 9 shows a composite difference of wave activity flux (Takaya \& Nakamura, 2001) and geostrophic streamfunction between positive AO 


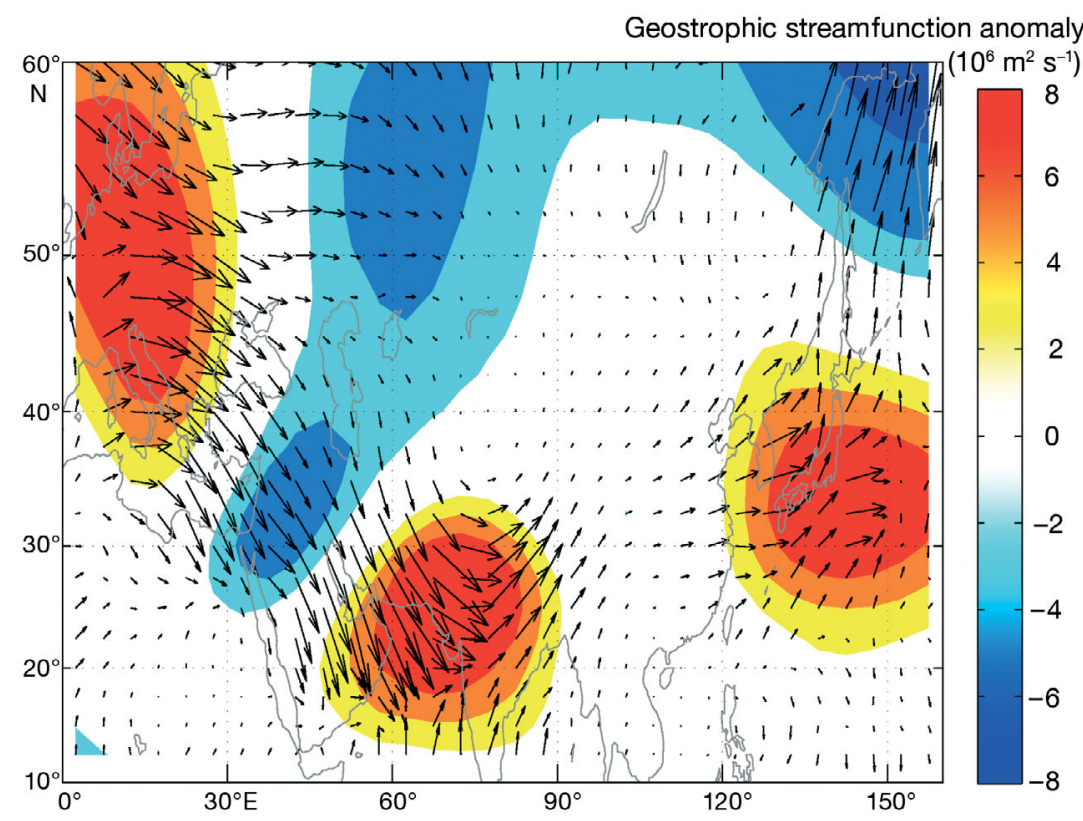

Fig. 9. Composite difference of wave activity flux $\left(\mathrm{m}^{2} \mathrm{~s}^{-2}\right)$ and geostrophic streamfunction $\left(\mathrm{m}^{2} \mathrm{~s}^{-1}\right)$ at $200 \mathrm{hPa}$ level between positive Arctic Oscillation (AO) phase and climate means (max. wave activity flux $5.4 \mathrm{~m}^{2} \mathrm{~s}^{-1}$ ). Arrows: horizontal component of wave activity flux based on geostrophic streamfunction anomalies (colour shaded) calculated as values for positive AO years minus climate means. The selected years are 1990, 1993, and 2002, in which AO index values are greater than 1 standard deviation and absolute values of Nino 3.4 SST are below 0.5 standard deviation

phases and climate means. To highlight the pure impacts of the AO rather than the ENSO on MEJS and SBT, 3 years are selected, i.e. 1990, 1993, and 2002, in which AO index is larger than 1 standard value and the absolute value of Niño 3.4 SST is below 0.5 standard value. On the map of composite difference, when $\mathrm{AO}$ is in a positive phase, a wave trainlike pattern occurs emanating downstream from the Europe to South Asia, with positive geostrophic streamfunction anomalies located both over the Europe $\left(40^{\circ}-60^{\circ} \mathrm{N}, 0-30^{\circ} \mathrm{E}\right)$ and northwest India $\left(10^{\circ}-30^{\circ} \mathrm{N}, 60^{\circ}-90^{\circ} \mathrm{E}\right)$, and a negative geostrophic streamfunction anomaly over West Asia $\left(30^{\circ}-40^{\circ} \mathrm{N}\right.$, $30^{\circ}-40^{\circ} \mathrm{E}$ ). Horizontal wave activity flux is superimposed over the wave train. The horizontal wave activity flux suggests that the wave train originates in Europe, spreading across northern Africa to northwest India. There are some studies dealing with this phenomenon. Suo et al. (2010) constructed this wave train in geopotential height field at $500 \mathrm{hPa}$ level using a one point correlation map. Their study suggested that when the positive height anomaly over the Europe strengthens, the positive height anomaly over West Asia also strengthens and consequently intensifies the SBT. All the processes are associated with enhanced MEJS that works as waveguide to induce the wave propagation. In turn, the intensified SBT over the BOB may transport more water vapor transport from the BOB to central-southern China, providing favorable weather conditions for the occurrence of precipitation extreme events. It is worth noting that, although Fig. 9 clearly suggests a possible mechanism that links AO to MEJS and SBT, this would require verification by numerical modeling that is beyond the scope of this study.

\section{CONCLUSIONS}

In this study, we have examined the relationship between the $\mathrm{AO}$ and the frequency of extreme precipitation over China during the period 1954-2009. The results show that the $\mathrm{AO}$ has a positive correlation with the P80th over China during January to February. Of all 287 stations, 238 stations have positive correlations and 90 stations are positively significant above the $95 \%$ confidence level. The stations with high positive correlations are mainly located over central-southern China. The correlation coefficient between the AO and the regional mean P80th over central-southern China is 0.55 , significant at the $99 \%$ confidence level.

In addition, we compared the AO-related P80th anomalies and the ENSO-related P80th anomalies. A large-scale spatial inconsistency exists between the AO-P80th relationship and the ENSO-P80th relationship. The AO may play a more important role in influencing the P80th over central-southern China. However, the ENSO's possible effect on the P80th is confined to the southern coastal region of China. The AO-P80th relationship over central-southern China is similar when the ENSO-related component is excluded from the original time series.

The AO-P80th relationship over central-southern China is likely related to 2 factors: MEJS and strong SBT activity. A positive AO phase is accompanied by intensified MEJS and SBT. These enhance the weather disturbances from West Asia to the BOB. Consequently, a stronger SBT activity may enhance both moisture supply and ascending air motions over central-southern China. As a result, precipitation and the frequency of extreme precipitation events increase over central-southern China. 
Acknowledgements. This research was supported by projects 2007BAC29B02, 2012CB955400, and 2008AA121704. R. M. was supported by the China Postdoctoral Science Foundation under Grant No. 20090460222 and Grant No. 201104062.

\section{LITERATURE CITED}

Angell JK (2006) Changes in the 300-mb North circumpolar vortex, 1963-2001. J Clim 19:2984-2994

Bao Q, Yang J, Liu Y, Wu G, Wang B (2010) Roles of anomalous Tibetan Plateau warming on the severe 2008 winter storm in central-southern China. Mon Weather Rev 138:2375-2384

Gao H, Yang S (2009) A severe drought event in northern China in winter 2008-2009 and the possible influences of La Niña and Tibetan Plateau. J Geophys Res 114:D24104. doi:10.1029/2009jd012430

> Gimeno L, Torre LDL, Nieto R, García R, Hernández E, Ribera $\mathrm{P}$ (2003) Changes in the relationship NAO-Northern hemisphere temperature due to solar activity. Earth Planet Sci Lett 206:15-20

Gong DY, Ho CH (2003) Arctic oscillation signals in East Asian summer monsoon. J Geophys Res 108:4066. doi:10. 1029/2002JD002193

Gong DY, Wang SW (2003) Influence of Arctic Oscillation on winter climate over China. J Geogr Sci 13:208-216

Gong DY, Wang SW, Zhu JH (2001) East Asian winter monsoon and Arctic Oscillation. Geophys Res Lett 28: 2073-2076

Gong DY, Wang SW, Zhu JH (2004) Arctic Oscillation influence on daily temperature variance in winter over China. Chin Sci Bull 49:637-642

Gong DY, Mao R, Fan YD (2006) East Asian dust storm and weather disturbance: possible links to the Arctic Oscillation. Int J Climatol 26:1379-1396

Gong DY, Yang J, Kim SJ, Gao YQ, Guo D, Zhou T, Hu M (2011) Spring Arctic Oscillation-East Asian summer monsoon connection through circulation changes over the western North Pacific. Clim Dyn 37:2199-2216

Hoerling MP, Ting M, Kumar A (1995) Zonally flow-stationary wave relationship during El Niño: Implications for seasonal forecasting. J Clim 8:1838-1852

Li J, Wang J (2003) A modified zonal index and its physical sense. Geophys Res Lett 30:1632. doi:10.1029/2003GL 017441

> Mao R, Gong DY, Bao JD, Fan YD (2011a) Possible influence of Arctic Oscillation on dust storm frequency in North China. J Geogr Sci 21:207-218

Mao R, Ho CH, Shao Y, Gong DY, Kim J (2011b) Influence of Arctic oscillation on dust activity over northeast Asia.

Submitted: January 17, 2011; Accepted: August 4, 2011
Atmos Environ 45:326-337

Nakamura T, Tachibana Y, Honda M, Yamane S (2006) Influence of the northern hemisphere annular mode on ENSO by modulating westerly wind bursts. Geophys Res Lett 33:L07709. doi:10.1029/2005GL025432

Quadrelli R, Wallace JM (2002) Dependence of the structure of the northern hemisphere annular mode on the polarity of ENSO. Geophys Res Lett 29:2132. doi:10.1029/2002GL 015807

Suo MQ, Ding Y (2009) The structures and evolutions of the wintertime southern branch trough in the subtropical westerlies. Chinese J Atmos Sci 33:425-442

Suo MQ, Ding Y, Wang ZY (2010) Relationship between Rossby wave propagation in southern branch of westerlies and the formation of the southern branch trough in wintertime. J Appl Meterol Sci 19:731-740

Takaya K, Nakamura H (2001) A formulation of a phaseindependent wave-activity flux for stationary quasigeostrophic eddies on a zonally varying basic flow. J Atmos Sci 58:608-627

Thompson DWJ, Wallace JM (1998) The Arctic oscillation signature in the wintertime geopotential height and temperature fields. Geophys Res Lett 25:1297-1300

Thompson DWJ, Wallace JM (2001) Regional climate impacts of the Northern Hemisphere annular mode. Science 293:85-89

Wang J, Ikeda M (2000) Arctic oscillation and Arctic sea-ice oscillation. Geophys Res Lett 27:1287-1290

Wen M, Yang S, Kumar A, Zhang PQ (2009) An analysis of the large-scale climate anomalies associated with the snowstorms affecting China in January 2008. Mon Weather Rev 137:1111-1131

- Wettstein JJ, Mearns LO (2002) The influence of the North Atlantic-Arctic Oscillation on mean variance and extremes of temperature in the northeastern United States and Canada. J Clim 15:3586-3600

Wu BY, Wang J (2002) Winter Arctic Oscillation, Siberian High and East Asian winter monsoon. Geophys Res Lett 29:1897. doi:10.1029/2002GL015373

> Yang S, Lau KM, Yoo SH, Kinter JL, Miyakoda K, Ho CH (2004) Upstream subtropical signals preceding the Asian summer monsoon circulation. J Clim 17:4213-4229

> Zhang R, Sumi A (2002) Moisture circulation over East Asia during the El Niño episode in northern winter spring and autumn. J Meteorol Soc Jpn 80:213-227

Zhang ZY, Gong DY, Hu M, Guo D, He XZ, Lei YN (2009) Anomalous winter temperature and precipitation events in southern China. J Geogr Sci 19:471-488

Zhou TJ, Yu RC (2005) Atmospheric water vapor transport associated with typical anomalous summer rainfall patterns in China. J Geophys Res 110:D08104. doi:10.1029/ 2004JD005413

Proofs received from author(s): November 14, 2011 